\title{
ANALYSIS OF NON-INDUCTIVE CURRENT DRIVE FROM ECCD AND BOOTSTRAP ON T-10
}

NWV 184991

\author{
by \\ JOHN LOHR, R.W. HARVEY, R.A. JAMES, T.C. LUCE, \\ C.C. PETTY, V.V. ALIKAEV, A.A. BAGDASAROV, \\ A.A. BORSHCHEGOVSKY, Yu.V. ESIPCHUK, YU.A. GORELOV, \\ A.B. PIMENOV, K.A. RAZUMOVA, I.N. ROI, \\ V.M. TRUKHIN, and N.L. VASIN
}

OCTOBER 1991

\section{GENIERAL ATOMICS}




\section{DISCLAIMER}

This report was prepared as an account of work sponsored by an agency of the United States Government. Neither the United States Government nor any agency thereof, nor any of their employees, makes any warranty, express or implied, or assumes any legal liability or responsibility for the accuracy, completeness, or usefulness of any information, apparatus, product, or process disclosed, ir represents that its use would not infringe privately uwned rights. Reference herein to any s jecific commercial product, process, or service by trade name, trademark, manufacturer, or otherwise, does not necessarily constitute or imply its endorsement, recommendation, or favoring by the United States Government or any agency thereof. The views and opinions of authors expressed herein do not necessarily state or reflect those of the United States Government or any agency thereof. 


\section{ANALYSIS OF NON-INDUCTIVE CURRENT DRIVE FROM ECCD AND BOOTSTRAP ON T-10} C.C. PETTY, V.V. ALIKAEV ${ }^{\dagger}$ A.A. BAGDASAROV, ${ }^{\dagger}$ A.A. BORSHCHEGOVSKY, ${ }^{\dagger}$ Yu.V. ESIPCHUK, ${ }^{\dagger}$ Yu.A. GORELOV, ${ }^{\dagger}$

A.B. PIMENOV, ${ }^{\dagger}$ K.A. RAZUMOVA, ${ }^{\dagger}$ I.N. ROI, ${ }^{\dagger}$ V.M. TRUKHIN, ${ }^{\dagger}$ and N.L. VASIN ${ }^{\dagger}$

This is a preprint of a paper presented at the Ninth Topical Conference on the Radio Frequency, August 19-21, 1991, in Cnarleston, South Carolina, and to be printed in the Proceedings.

Work supported by

U.S. Department of Energy

Contract Nos. DE-AC03-89ER51114, W-7405-ENG-48 and the Soviet Fusion Program

* Lawrence Livermore National Laboratory, USA.

† Kurchatov Institute for Atomic Energy, USSR.

GENERAL ATOMICS PROJECT 3466 OCTOBER 1991

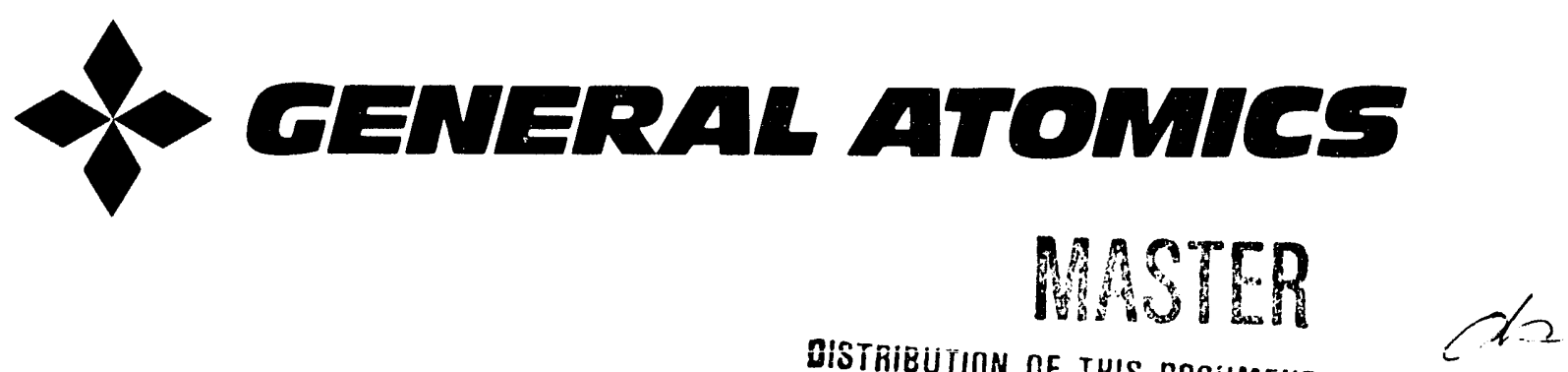




\section{ANALYSIS OF NON-INDUCTIVE CURRENT DRIVE FROM ECCD AND BOOTSTRAP ON T-10*}

John Lohr, R.W. Harvey, R.A. James, ${ }^{\dagger}$ T.C. Luce, C.C. Petty

General Atomics, P.O. Box 85608, San Diego, California 92186-9784

V.V. Alikaev, A.A. Bagdasarov, A.A. Borshchegovsky, Yu.V. Esipchuk, Yu.A. Gorelov, A.B. Pimenov, K.A. Razumova, I.N. Roi, V.M. Trukhin, N.L. Vasin

Kurchatov Institute for Atomic Energy, Moscow, USSR

\section{ABSTRACT}

The combination of electron cyclotron current drive and the bootstrap effect has produced completely non-inductively driven current of $75 \mathrm{kA}$ for up to $200 \mathrm{msec}$ in the $\mathrm{T}-10$ tokamak. At higher values of plasma current $\mathrm{I}_{p} \sim 175 \mathrm{kA}, \mathrm{I}_{p} \geq 60 \mathrm{kA}$ was maintained by ECCD. These experiments have been modeled with the coupled ray training and transport codes TORAY and ONETWO. Within the uncertainties in the experimental data, the calculations show that the sum of bootstrap and ECCD substantially exceeded the not programmed plasma current.

\section{EXPERIMENT}

Up to eleven gyrotrons were operated during these experiments. Nine gyrotrons at $81.3 \mathrm{GHz}$ were arranged in three groups consisting of 4,3 and 2 tubes respectively separated by $90^{\circ}$ toroidally. These tubes injected into the torus at an angle of $21^{\circ}$ to the radial at the injection point from the low field side in the ordinary mode for ECCD. The gyrotron groups were operated serially, therefore absorbed power of approximately $0.75 \mathrm{MW}$ for periods of up to $0.5 \mathrm{sec}$ was achieved. When these groups were superimposed, power in excess of 1.0 MW was absorbed, although this was for shorter durations up to $0.25 \mathrm{sec}$. The rema aing two tubes were at $75 \mathrm{GHz}$ and injected approximately $0.65 \mathrm{MW}$. These two tubes injected radially and were used for heating only. The two resonances are $12 \mathrm{~cm}$ apart in T-10.

A wide range of parameters was explored during these experiments. $I_{p}=75-$ $175 \mathrm{kA} ; \bar{n}_{e}=0.5-1.6 \times 10^{19} / \mathrm{m}^{3}$. Ohmic electron temperatures were $\mathrm{T}_{e}(0) \sim 1.5 \mathrm{keV}$ and this increased to $\mathrm{T}_{e}(0) \sim 7 \mathrm{keV}$ during $\mathrm{ECH}$. The primary uncertainty in the analysis came from determination of $Z_{\text {eff }}$, which increased from $\sim 2$ to $\geq 5$ during the ECH pulses. A $B_{T}$ scan showed largest ECCD for $2.78 \mathrm{~T}$ and generally this was the value used. For this field, the absorption at $81.3 \mathrm{GHz}$ coincides with the peak value of $\mathrm{T}_{\mathrm{e}}$.

\section{ANALYSIS}

Althe wh the data were distributed throughout the parameter space described above, two re imes were of particular interest. This report will focus on them:

Low current regime $\mathrm{I}_{p}=75 \mathrm{kA} \mathrm{T} \mathrm{T}_{e}(0) \sim 5 \mathrm{keV} \bar{n}_{e} \sim 1.0 \times 10^{19} / \mathrm{m}^{3}$.

High current regime $\mathrm{I}_{p}=175 \mathrm{kA} \mathrm{T} \mathrm{T}_{e}(0) \sim 7 \mathrm{keV} \bar{n}_{e} \sim 1.1 \times 10^{19} / \mathrm{m}^{3}$.

- This work was supported by the U.S. Department of Energy under Contract Nos. DE-AC0389ER51114, W-7405-ENG-48 and the Soviet Fusion Program.

$\dagger$ Lawrence Livermore National Laboratory, Livermore, California 94550 
The parallel current density is given by

$$
j_{\|} \sim j_{\Omega}+j_{\text {boot }} \pm j_{\mathrm{ECCD}}
$$

The neoclassical bootstrap contribution is parameterized as

$$
j_{\text {boot }} \sim-\frac{\epsilon^{1 / 2} n T}{\mathrm{~B}_{\theta}}\left(C_{1} \frac{1}{n} \frac{d n}{d r}+C_{2} \frac{1}{\mathrm{~T}_{e}} \frac{d T_{e}}{d r}-C_{3} \frac{1}{\mathrm{~T}_{e}} \frac{d T_{i}}{d r}\right),
$$

Where $j_{\Omega}$ is the ohmic current and $j_{\mathrm{ECCD}}$ is the ECCD current, either in the same or the opposite direction to the ohmic. The bootstrap current is the same direction as the ohmic current for all but the most pathological profiles, and is enhanced by large temperatures and densities and their gradients and by low ohmic current operation. The quantities $C_{n}$ are constants or slowly varying functions of temperature and density.

The analysis was performed by the coupled codes TORAY, which performed ray tracing and power deposition calculations and ONETWO, which evolved the kinetic profiles self-consistently. The density profile was not evolved and the energy confinement was forced to follow a $\mathrm{P}^{-1 / 2}$ parameterization. The fundamental transport model was approximately Alcator scaling, however the calculated electron temperature during ECH was matched to the experimental value by adjusting the constant coefficient of $\chi_{e}$. The effective $\chi_{e}$ thus obtained was about $75 \%$ of the Alcator value.

\section{LOW CURRENT REGIME}

In the low current regime the entire plasma current was maintained non-inductively by a combination of ECCD and bootstrap. From Eq. (2) it is seen that the lower plasma current operation is expected to enhance the bootstrap current fraction and this is borne out by the simulation.

The calculation for this situation is sumriarized in Fig. 1. At $100 \mathrm{msec}, 650 \mathrm{~kW}$ of heating power was applied, followed $100 \mathrm{msec}$ later by $750 \mathrm{~kW}$ of ECCD in the codirection. Even during the period of heating only, the bootstrap current was nearly equal to $75 \mathrm{kA}$ and the ohmic current decreased to a few $\mathrm{kA}$. With the additional ECCD power, which drove $\sim 25 \mathrm{kA}$, the bootstrap current increased to $\mathrm{I}_{\text {boot }}>100 \mathrm{kA}$ and to maintain the programmed value, the ohmic current reversed direction and approximately $-60 \mathrm{kA}$ was driven.

The experimental loop voltage traces and $T_{e}(r)$ profile are seen in Fig. 1 to be well represented by these calculations. In the experiment a reverse ECCD case was run and

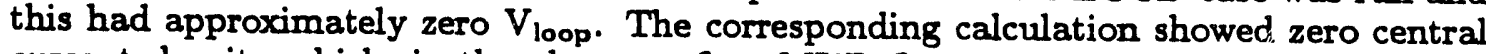
current density which, in the absence of an MKD fluctuation model, was unphysical. As expected from the driving terms for the bootstrap current, both $j(r)$ and $q(r)$ have off-axis peaks.

\section{HIGH CURRENT REGIME}

The TORAY/ONETWO simulation for the high current regime indicates that an ECCD current of $70 \mathrm{kA}$ was maintained while the bootstrap current was $\sim 60 \mathrm{kA}$. Heating power was $640 \mathrm{~kW}$ and current drive power was $1.46 \mathrm{MW}$. In order to maintain the programmed total current of $175 \mathrm{kA}$, an ohmic current, of $\sim 40 \mathrm{kA}$ was required during ECCD. These results are summarized in Fig. 2 in which the experimental and calculated surface loop voltage traces for ECCD parallel to the ohmic current are shown. The experimental loop voltage is coupled to the vertical field, therefore no significance 
should be attached to the time lag in the $V_{\text {loop }}$ decrease following the initiation of $E C H$. Although $T_{e}(0)$ is reproduced by the calculation, the experimental profile is more peaked than the calculation. This discrepancy is attributed to uncertainties in the experimental measurements and the choice of the transport model. A $\mathrm{Z}_{\text {eff }}$ value of 5.5 with flat radial profile was used and this gave good agreement with the experimental loop voltage difference for the co- and counter-ECCD cases while simultaneously reproducing $\mathrm{T}_{\mathrm{e}}(0)$

\section{CONCLUSION}

Complete non-inductive current drive from ECCD and the bootstrap effect has been observed on T-10. Electron cyclotron current drive in excess of $60 \mathrm{kA}$ has also been achieved. The experiment has been modeled by TORAY/ONETWO the calculations support this conclusion by indicating a sum of bootstrap and ECCD well in excess of the plasma current.
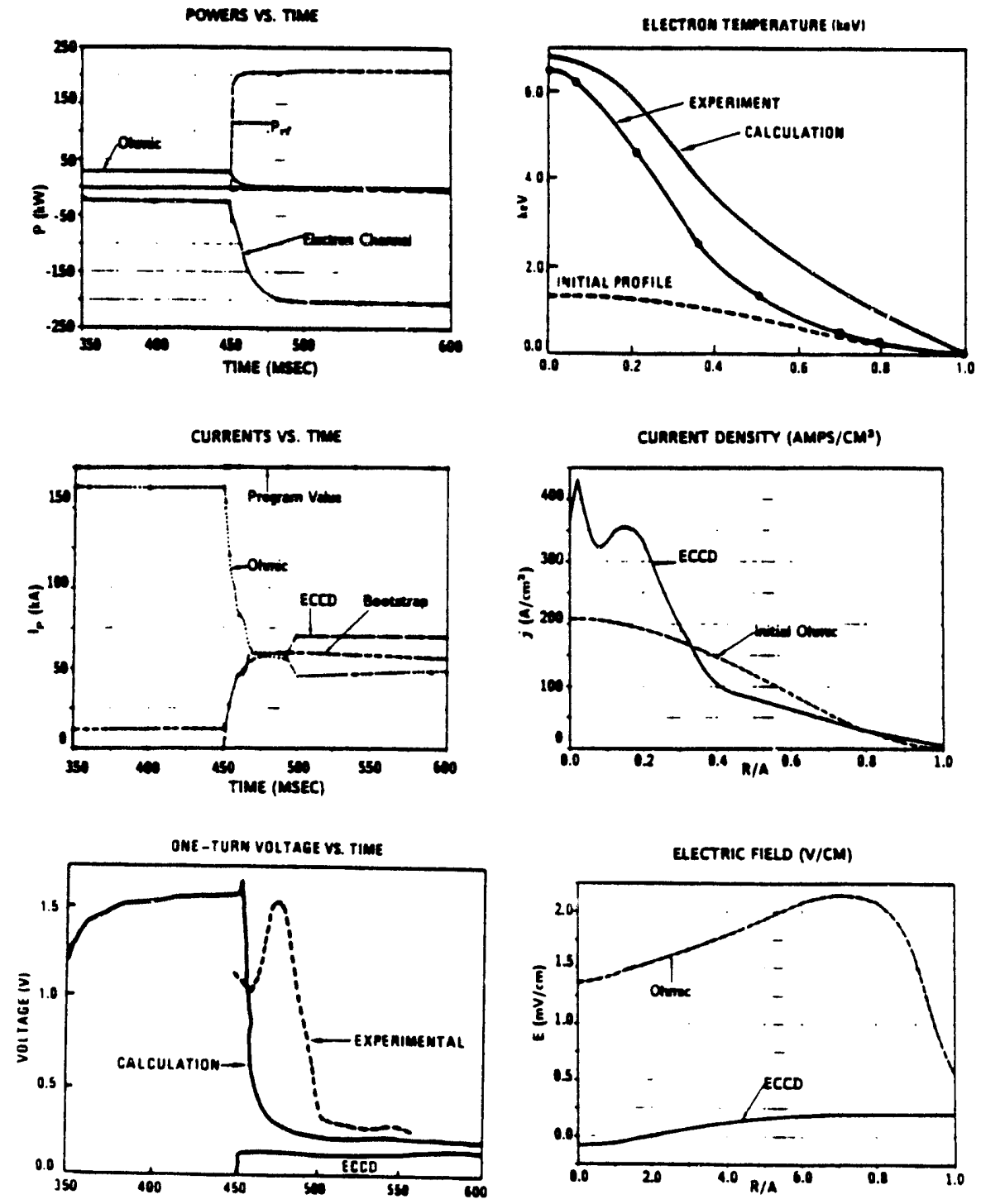

Fig. 1. Summary plots for the high density regime in which the bootstrap and ECCD are approximately equal. The calculated loop voltage approximately equals the experimental value at long times. The residual inductive current is approximately $40 \mathrm{kA}$. 

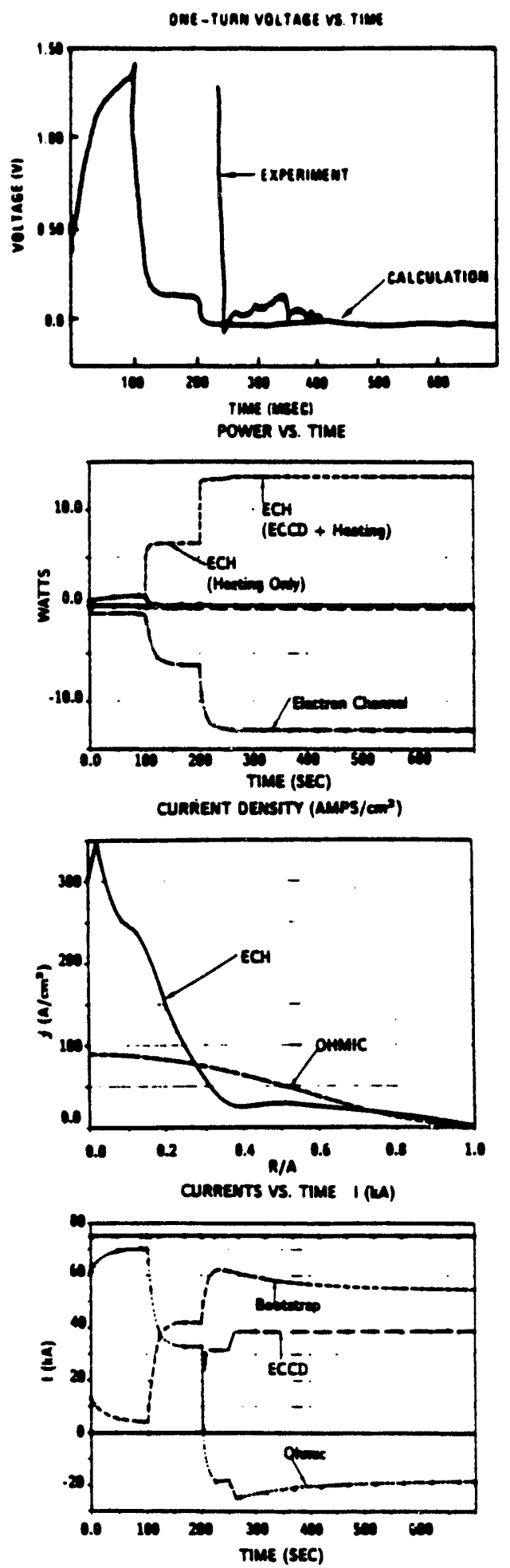

Fig. 2. Summary plots for the low density regime in which bootstrap plus ECCD account for the entire current. In order to maintain the program value, the inductive current reverses direction and the loop voltage is slightly negative. 

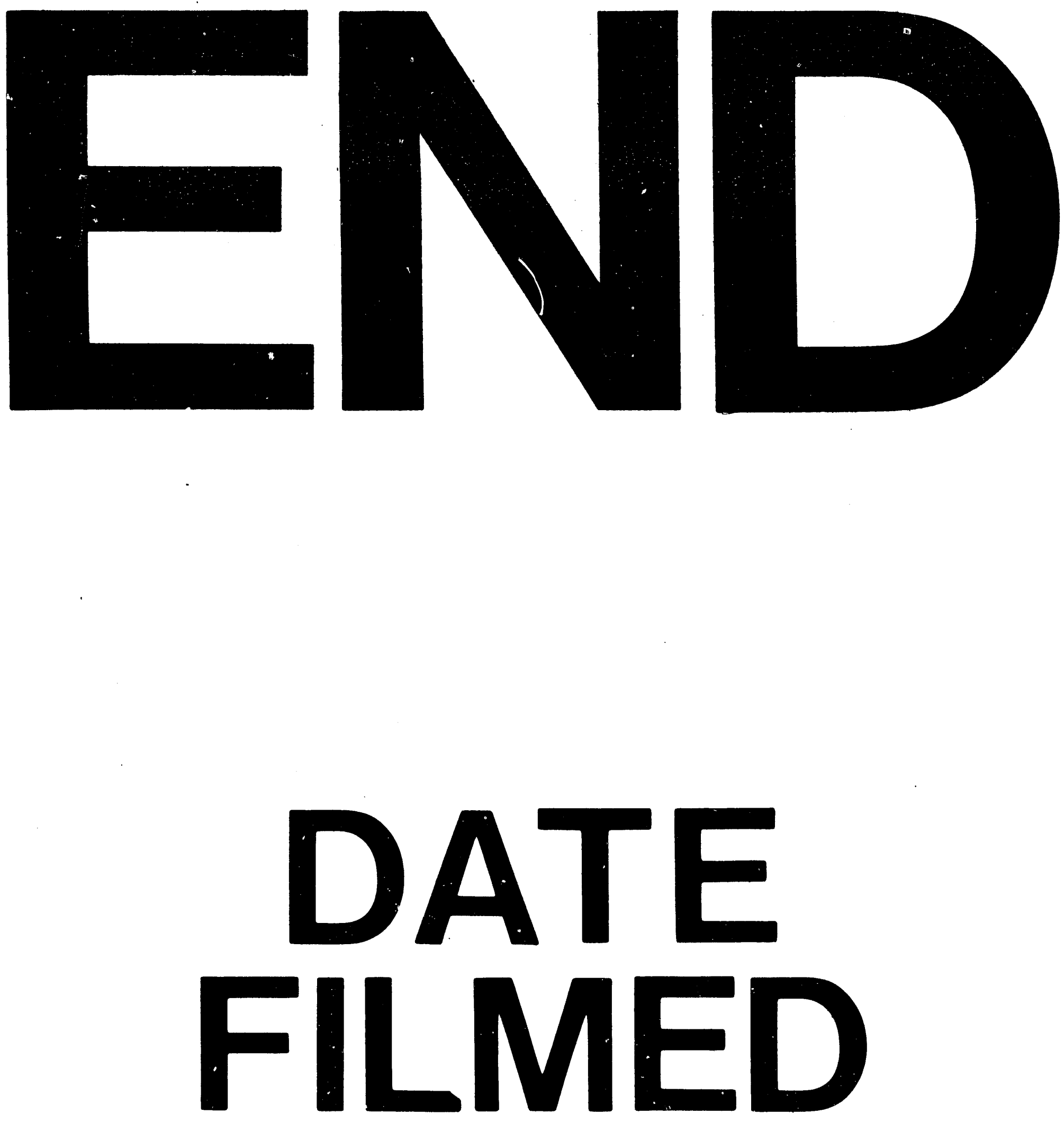

1

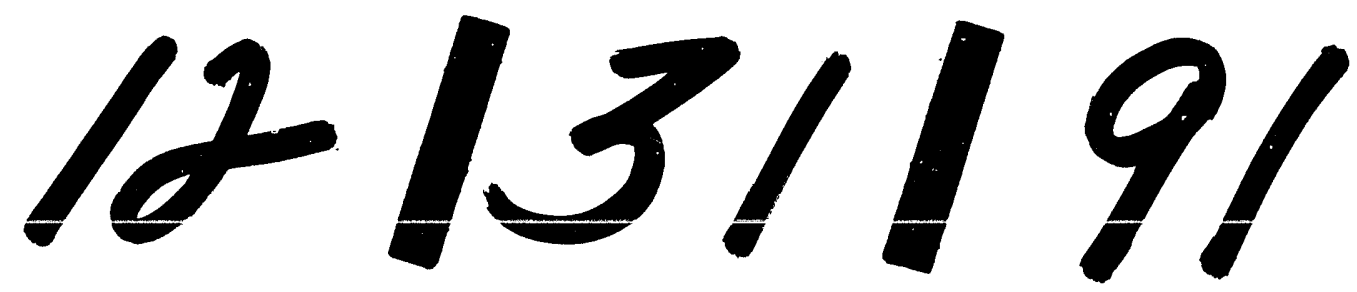

I. 
